\title{
Assessing the impact of evidence summaries in library and information practice
}

\author{
Lorie A. Kloda, Denise Koufogiannakis, Alison Brettle
}

\section{Abstract \\ Objective}

This study developed, validated and administered an instrument to investigate the impact of research evidence summaries published in the journal, Evidence Based Library and Information Practice.

\section{Methods}

Using the critical incident technique, this mixed methods study began by developing and testing a survey questionnaire, disseminating it to readers of the journal and conducting follow-up interviews with a subsample.

\section{Findings}

A total of 86 practitioners responded to the survey and 13 took part in interviews. Evidence summaries led to impact at four levels: librarian knowledge, librarian practice, workplace practice, and library users. The instrument was revised as a result of the findings.

\section{Conclusion}

This study provides unique insight into whether evidence summaries are an effective means of bridging the research-practice gap for the library community and its scholarly communication channels. The validated impact assessment instrument may also be adapted for other means of disseminating research in library and information practice.

\section{Authors}

Lorie A. Kloda is the Assessment Librarian at McGill University. She is currently the Editor-in-Chief of the journal, Evidence Based Library and Information Practice (EBLIP).

Email: lorie.kloda@mcgill.ca

Denise Koufogiannakis is Collections and Acquisitions Coordinator at the University of Alberta Libraries in Edmonton, Alberta, Canada.

Alison Brettle is a Reader in Evidence Based Practice at the University of Salford. She has been involved in a range of editorial roles with EBLIP since its inception. 


\section{Introduction}

Research in library and information studies (LIS) has identified problems with translating research into practice, but no studies have tested methods that may prove to be effective solutions. To address this problem, this study investigates a potential solution by determining how evidence summaries of the LIS research literature published in the journal, Evidence Based Library and Information Practice (EBLIP), might contribute to bridging the gap between research and practice.

The objective of this study was to investigate the impact of evidence summaries on library and information professionals, their practice, and their users. This was carried out through the following stages:

1. Development of a tool to assess impact;

2. Use of the tool to:

a) determine how and why readers of evidence summaries use them;

b) understand how evidence summaries impact knowledge, practice, users;

3. Use of the findings to validate and revise the tool.

It was anticipated that the feedback from evidence summary readers would uncover the ways in which evidence summaries are being used and also demonstrate if reading evidence summaries resulted in positive, negative, or neutral (that is, no) impact on practice.

Three outcomes of the research were anticipated:

- A validated tool for assessing the impact of evidence summaries in library and information practice;

- Descriptive data on usage of evidence summaries published in EBLIP;

- An understanding of the impact of reading evidence summaries on LIS practitioners knowledge, practice, and user communities.

\section{Review of the literature}

The impact of research and its measurement is an important research topic, particularly at a time when value for money in public spending is paramount (Cruickshank et al., 2011). Research impact can be measured and discussed in a number of ways, but authors in LIS have long been concerned about the impact of LIS research on practice (for example, Haddow and Klobas, 2004; Eve and Schenk, 2006; Cruikshank, Hall and Taylor-Smith, 2011; Hall, 2011; Buckley Woods and Booth; 2013). According to Haddow and Klobas (2004), research and practice should be mutually beneficial and practice should benefit from research findings. However, whilst a review of the literature highlighted that multiple authors have found that practitioners perceive much of LIS research as irrelevant (Cruikshank, Hall and Taylor-Smith, 2011), another review found that very few papers directly examined what type of research is relevant to LIS practitioners (Buckley Woods and Booth, 2013). 
Buckley Woods and Booth (2013) found that practitioners engage with LIS research in three ways: by conducting their own research, by working collaboratively with academics, and as consumers of research. This paper is concerned with the latter of these in relation to evidence based practice (or evidence based library and information practice), a key area of practitioner engagement with research (Buckley Woods and Booth, 2013). Haddow and Klobas (2004) suggest that communication between research and practice is a weakness that has been identified within the literature for over 25 years. In their critical review of the literature on this issue, they identified 11 forms that the research to practice gap may take: knowledge, cultural, motivation, relevance gap, immediacy, publication, reading, terminology, activity, education gap, and temporal. Haddow and Klobas (2004) also examined strategies to close the research practice gap and found that the only strategy that is supported by research evidence is to include research reports in practitioner publications. This finding was supported by Eve and Schenk (2006) who found that practitioners are unlikely to read academic journals, due to inaccessibility both in terms of journal availability and writing style.

Evidence summaries, or synopses of research, are tools which originated in evidence based health care (Wyer and Rowe, 2007). Evidence summaries provide a critical appraisal synthesis for a specific research article so that LIS practitioners may more readily determine if the evidence in that research study is valid and reliable, and whether they can apply it to their own practice (Koufogiannakis, 2006). Evidence summaries have been included in the journal EBLIP since its inception in 2006, with more than 200 published between 2006-2011, which was the period of this study. EBLIP evidence summaries seek to overcome many of the gaps identified above by providing timely, accessible summaries which are relevant to practitioners, in an open access format.

Haddow and Klobas (2004) have called for further research to be undertaken on the effectiveness of including research reports in practitioner publications. Indeed, there is limited evidence to date of the effectiveness of evidence summaries, even within the health care field. The majority of literature in relation to evidence summaries within healthcare is in relation to their development (for example, Wyer and Rowe, 2007; Khangura et al., 2012). Evidence regarding their effectiveness and impact is mixed. Grad et al. (2011) found that evidence summaries attached to email alerts were rarely read by family physicians whilst Williams et al. (2010) found improved knowledge in paediatricians following an evidence summary intervention but no significant changes in practice. In contrast, modest changes in practice for targeted evidence summary interventions in relation to medication or prescribing have been found (Kunz et al., 2007; Majumdar, Tsuyuki and McAlister, 2007). Clearly, even within evidence based health care there is further work to be undertaken on measuring the impact of evidence summaries.

The main focus of the work described in this paper is on evaluating the impact of evidence summaries on LIS practitioners. However, impact can be discussed in a number of ways, and it is important to consider what is meant by impact, before attempting to measure it. 
Impact is a concept receiving increasing recognition within the library literature, as libraries seek to demonstrate their value or to embrace evidence based library and information practice methods. Terminology surrounding impact is often used interchangeably (Brettle, 2009; Dunne et al., 2014) and there is often confusion as the concept of impact encompasses terms such as assessment, value, evaluation, effectiveness, outcomes and outputs. At its simplest level impact is about determining whether "something makes a difference" (Marshall, 1995). More explicitly, in relation to LIS services, impact has been defined as:

a range of dimensions concerning effectiveness of services, encompassing the effects of actions and services on those served including users, organisations and wider stakeholders.

(Cullen and Esson, 2007, 1)

Impact has also been defined in relation to the use of clinical information retrieval technology as "any change, consequence, effect, influence, modification or outcome associated with the use of that technology" (Pluye et al., 2005). This definition appears to overcome the issues regarding interchangeable terms associated with the impact of LIS services, as well as introducing concepts which are related to evidence based practice, such as effectiveness and outcomes. If impact is partly about effectiveness, it is also related to outcome, as "outcome measures are used to determine the effectiveness of an intervention (whether the intervention works)" (Brettle et al., 2011). Impact measures seek to establish whether the intervention has made a difference on the stakeholders involved, and these may not be immediate, tangible or direct (Brettle et al., 2011; Urquhart 2004).

This paper does not focus on the impact of LIS services per se, however the issues are the same in that the impact of the evidence summaries on LIS practitioners may not be immediate, tangible, or direct and therefore evaluating their impact is likely to be complex. It has been suggested that because of this complexity, looking for immediate or direct impacts may not be useful (Urqhuart, 2004). Therefore, the focus should be on how LIS can "contribute" to impact for its stakeholders rather than a direct measurement of impact (Urquhart, 2004; Abels, Cogdill and Zach, 2004).

Markless and Streatfield (2006) suggest that outcomes are not easily identifiable, occur over the long term and can be categorised as four types of change affecting library users: affective (effects on attitudes and perceptions); knowledge based; behavioural (doing things differently) and competence based (doing things more effectively). These categories are conceptually similar to those identified by Pluye et al. (2005) in their research on impact of information retrieval systems on health professionals. From their review of the literature, Pluye et al. (2005), identified impacts relating to practice improvement (behavioural), learning (knowledge based), recall (affective), reassurance (affective), and confirmation (affective). However, Pluye et al. (2005) also noted that impact could be negative as information retrieval may generate frustration or complete dissatisfaction or there may be no impact when there is notenough or too much information. This concept of impact was encompassed into a scale which sought to measure the cognitive impacts of information on health professionals (Pluye et al., 2005). 


\section{Methods}

The research was composed of three phases. The first phase was the design of an instrument to assess impact. The second phase was the use of the instrument on a sample of evidence summary readers to determine impact, and the third phase of the study consisted of further data gathering and analysis of a subset of survey respondents to confirm the findings and suggest changes to the instrument. This study was approved by two institutional review boards and consent was obtained from participants for phases two and three separately.

\subsection{Development and face validation of an instrument to assess the impact of evidence summaries}

For the first phase of the study, the researchers used an existing instrument as a point of departure for the development of an instrument for assessing impact in LIS. The Impact Assessment Method was developed by McGill University researchers in family medicine (Grad, Pluye and Beauchamp, 2006; Pluye et al., 2005; Pluye et al., 2009; Pluye et al., 2010), and was successfully adapted by McGowan et al. (2008). As the Impact Assessment Method was previously tested with evidence summaries in health care, and was well documented and validated, the researchers felt it could be adapted for evidence summaries within LIS practice.

The Impact Assessment Method measured impacts on cognition (knowledge), clinical practice, and patients. For the present study, the researchers retained the three areas of impacts, renaming these: impacts on librarian knowledge, impacts on librarian practice, and impacts on library users. The individual items within the instrument were adapted for the LIS population.

The drafted instrument was then sent to members of the editorial team of the journal, EBLIP, as well as to other experts, including colleagues and the authors of the original Impact Assessment Method, for feedback, and the instrument was revised to incorporate suggested changes. This step was to ensure the instrument's face validity.

The instrument was designed to be used in conjunction with the critical incident technique. The critical incident technique asks participants to describe a specific instance of where and how they have used information as a result of an intervention. It is a powerful tool for capturing specific instances of impact (Markless and Streatfield, 2006; Weightman and Williamson, 2005) and is advocated for use in the health library sector (Weightman et al., 2008; Brettle et al., 2011). It also has the advantage of being able to capture and provide detailed information of impact from a wide, dispersed group, such as the participants in this survey.

\subsection{Survey of evidence summary readers}

Following the development and face validation of the questionnaire, potential participants for the second phase of the study were invited to participate using multiple recruitment strategies. A letter of invitation was disseminated through 
multiple online channels, including email lists, the EBLIP journal's homepage, emails to approximately 3000 registered journal readers, and announcements on Twitter. In addition, for a three-month period, when someone viewed an evidence summary from one of the previous four issues of the EBLIP journal, a pop-up dialogue box appeared with the invitation. For all the above methods, a link was provided to a form for submitting an email address for those interested. A total of 153 usable email addresses were obtained using these combined methods.

The 153 evidence summary readers were emailed an invitation to complete the survey. Survey data were gathered using LimeSurvey software, and responses were gathered confidentially. The software also permitted reminders to be sent to non-responders and for the calculation of a response rate. Up to two reminders were sent to those who had not completed the survey, the first after three weeks, and the last one at six weeks. A total of 86 completed responses were collected.

The survey requested that participants identify a recently-read evidence summary and answer the questions with reference to that specific evidence summary. This way, all impacts reported would be associated with a specific evidence summary and therefore linked to a "critical incident." At the end of the survey, respondents were invited to provide their contact information should they wish to participate in an interview for the third phase of the study. The complete survey is available in Appendix A.

The survey response rate was $56 \%$. Descriptive data from the survey were analysed quantitatively in Microsoft Excel. Responses from the open-ended questions were compiled and analysed thematically and summarised by all three researchers.

\subsection{Interviews with subset of survey respondents}

The interview phase of the study was designed to provide for more depth of understanding of respondents' interpretation of the instrument as well as additional details regarding the critical incidents reported in the survey.

All 24 survey respondents who indicated they would be willing to participate in the third phase of this study were contacted and invited to be interviewed. The researchers set out to recruit a subsample of the survey participants representing maximum variation, that is, readers of the EBLIP journal from various regions, in various library sectors, and with different levels of experience. The 13 participants who responded to the invitation were scheduled for an interview (online or inperson) with one of the three authors based on availability.

Interviews were conducted either in-person or online using voice-over-internet protocol (VOIP) software (Skype). An interview schedule (Appendix B) was used to guide the interviews, which lasted between 30 to 45 minutes. Prior to each interview, the researcher conducting the interview emailed the participant information about the evidence summary to be discussed as a reminder. The interviews were intended to elicit information that would confirm and elaborate upon the survey responses relating to the critical incident identified by the participant in the survey. All interviews were recorded and later transcribed for analysis. 
The first three interviews conducted (one by each of the three researchers) were independently thematically analysed and compared. Following this, a list of thematic codes was developed to guide the analysis process for the remainder of the interviews. Each interview transcript was then coded by one researcher for the following: how the evidence summary was found; reasons why the evidence summary was consulted; the impact(s), uses, or changes as a result of reading the evidence summary; and any emergent ideas, concepts, or questions arising. As well, the characteristics of the interview participants were coded, including: setting, position, country, and education.

Once all the interviews were completed and the transcripts were analysed and coded, this information was matched to the participants' original survey responses to identify discrepancies and allow for further analysis. As a result of the data elicited from the interviews, the researchers were able to revise the list of possible impacts in all three areas (impacts on librarians' knowledge, impacts on librarian's practice, and impacts on library users).

\section{Findings}

\subsection{Findings from the survey}

Of the 86 individuals who responded to the survey, 62 (72\%) indicated that they had read an evidence summary. Only the 62 respondents were invited to continue the survey and complete the impact assessment instrument. Survey findings are therefore from this total $(\mathrm{N}=62)$. Most of the respondents were from the United States (35\%) and Canada (32\%), and an equal proportion were from the United Kingdom (8\%) and Australia (8\%). The remaining 17\% were from other countries. No other demographic information was gathered about the respondents, in order to keep the survey instrument as brief as possible.

The majority of respondents (82\%) indicated that they had read between 1 and 10 evidence summaries in the past 12 months, while a small number $(6 \%)$ indicated that they read more than 25 evidence summaries during that time period. In comparison, $53 \%$ of respondents reported having read more than 10 evidence summaries since the journal's inception in 2006.

The most common reason given for reading the evidence summary was "to answer a specific question or address a specific issue in my practice" (34\%, followed by "for personal continuing professional education" $(29 \%)$ and "for general interest or curiosity" (24\%), with the remaining responses $(13 \%)$ covering several other reasons.

Almost all respondents (94\%) had read the evidence summary they identified for their critical incident within the past 6 months, and $21 \%$ of these had read it within one week of completing the survey. Twenty-five different evidence summaries were identified by the respondents as critical incidents to respond to the impact assessment instrument. This means that several evidence summaries were named by multiple respondents.

Respondents reported what types of impacts resulted from reading the evidence summary. Multiple responses were permitted (Table 1). The most common impacts noted by respondents related to knowledge: that they learned something 
new from the evidence summary, that the summary prompted them to investigate further, or that it confirmed they were doing the right thing.

\begin{tabular}{|l|r|r|}
\hline Impact statement & $\begin{array}{r}\text { Frequency of } \\
\text { response (n) }\end{array}$ & $\begin{array}{r}\text { Percentage of total } \\
\text { responses (N=62) }\end{array}$ \\
\hline I learned something new & 36 & $42 \%$ \\
\hline It prompted me to investigate more & 23 & $27 \%$ \\
\hline It confirmed I did (I am doing) the right thing & 17 & $16 \%$ \\
\hline I recalled something I already knew & 13 & $15 \%$ \\
\hline I was reassured & 11 & $13 \%$ \\
\hline My practice was (will be) improved & 9 & $10 \%$ \\
\hline Other & 1 & 0 \\
\hline $\begin{array}{l}\text { I was dissatisfied: There is a problem with the } \\
\text { presentation of this evidence summary }\end{array}$ & & $0 \%$ \\
\hline It is potentially harmful & & $1 \%$ \\
\hline
\end{tabular}

\section{Table 1: Impacts on knowledge}

The one response of dissatisfaction prompted another question which asked what the problem was. In this single instance, the problem identified was that there was "not enough information".

The 9 respondents $(10.5 \%)$ who chose the statement, "My practice was (will be) improved," were presented with a related question asking: "You reported: My practice was (will be) improved. What did you (or will you) do differently after reading the Evidence Summary?" Table 2 shows how those 9 respondents described the impact of the evidence summary on their practice. Multiple responses were permitted. The results varied, possibly depending upon the subject area covered by the evidence summary. Responses in the "other" category included "impacted research method," "impacted reader's advisory service," and "general knowledge".

The question relating to impact on library users asked, "If reading this evidence summary resulted in some change to your individual practice, do you think it led to an impact on anyone within the community you serve or environment in which you work?" This was an open question that allowed respondents to answer as they wished. Of the 62 respondents, 41(66\%) answered this question. In most instances, the comments hypothesised future potential impacts on users or 
reinforced knowledge or practice impacts, but did not identify outcomes on users. In 4 of the comments, respondents reported actual impact on library users. The impacts identified were all anecdotal, that is, these were changes observed by the respondent, and not measures by a formal method. Examples include assuming that their institution saved money and that students performed better on an assignment.

\begin{tabular}{|c|c|c|}
\hline Impact statement & $\begin{array}{l}\text { Frequency of } \\
\text { response (n) }\end{array}$ & $\begin{array}{r}\text { Percentage of total } \\
\text { responses }(\mathrm{N}=62)\end{array}$ \\
\hline Change my service approach & 5 & $6 \%$ \\
\hline Change my management approach & 4 & $5 \%$ \\
\hline Change my approach to teaching & 4 & $5 \%$ \\
\hline Change my professional approach & 4 & $5 \%$ \\
\hline Other & 3 & $3 \%$ \\
\hline Change my approach to collections & 1 & $1 \%$ \\
\hline
\end{tabular}

Table 2: Impacts on practice

\subsection{Findings from the interviews}

Thirteen survey respondents $(15 \%)$ indicated a willingness to participate in interviews to discuss their experiences further. Interview participants were primarily from academic settings $(n=9)$ and the remainder from hospital $(n=1)$ or teaching settings $(n=3)$. The majority held master's level credentials $(n=9)$, with 3 having an additional $\mathrm{PhD}$, and 1 a post-graduate diploma. The majority of the interview participants were from Canada $(n=6)$ and the United States $(n=4)$, and the other 3 were from the United Kingdom, Australia, and Hong Kong. Most of those interviewed were librarians $(n=6)$, and an additional 3 were librarians and also managers. One was support staff, and three were LIS academics. Three of the interviewees had previously had a formal connection with the journal, for example as an evidence summary writer or peer reviewer.

In general, the interviews confirmed the impacts reported in the survey and provided concrete examples, which the researchers were able to map to the impact statements. For instance, Participant 11, in the interview, explained that she searched for more articles on the topic after having read the evidence summary. On the questionnaire she had selected "It prompted me to investigate further." The interview therefore confirmed the finding from the questionnaire and provided a concrete behaviour to corroborate the impact statement she had selected.

Participant 89 also selected the impact statement, "It prompted me to investigate further." In this case, she went on to read the original publication on which the evidence summary was based. Participant 33 reported that "practice would be 
improved" and described writing a literature review and sharing the knowledge with her manager.

\begin{tabular}{|c|c|c|c|}
\hline Participant & $\begin{array}{l}\text { Impacts reported } \\
\text { Phase } 2\end{array}$ & $\begin{array}{l}\text { Impacts reported } \\
\text { Phase } 3\end{array}$ & $\begin{array}{l}\text { Remarks on commonalities } \\
\text { and discrepancies }\end{array}$ \\
\hline P-106 & $\begin{array}{l}\text { No impact statements } \\
\text { selected }\end{array}$ & $\begin{array}{l}\text { For teaching, so } \\
\text { nothing direct. } \\
\text { Recommended the } \\
\text { evidence summary to } \\
\text { students in her course }\end{array}$ & $\begin{array}{l}\text { The instrument does no capture } \\
\text { the impact of reading an } \\
\text { evidence summary on teaching } \\
\text { librarians or students in LIS or } \\
\text { recommending it as a reading. }\end{array}$ \\
\hline $\mathrm{P}-11$ & $\begin{array}{l}\text { "It prompted me to } \\
\text { investigate more." }\end{array}$ & $\begin{array}{l}\text { Searched for more } \\
\text { articles on topic }\end{array}$ & $\begin{array}{l}\text { This statement often means to } \\
\text { read the original publication or } \\
\text { otherwise to search for more } \\
\text { articles. }\end{array}$ \\
\hline $\mathrm{P}-33$ & $\begin{array}{l}\text { "My practice was } \\
\text { (will be) improved." } \\
\text { "Change my service } \\
\text { approach." } \\
\text { "Practice - Other." } \\
\text { general fund of } \\
\text { knowledge }\end{array}$ & $\begin{array}{l}\text { Wrote a literature } \\
\text { review } \\
\text { Shared information } \\
\text { with manager }\end{array}$ & $\begin{array}{l}\text { The instrument did not capture } \\
\text { the transmission of knowledge } \\
\text { to colleagues/peers through } \\
\text { writing reports or } \\
\text { recommendations, or } \\
\text { discussions. } \\
\text { "Learned something new" not } \\
\text { selected, perhaps reword to add } \\
\text { gaining knowledge. }\end{array}$ \\
\hline $\mathrm{P}-48$ & $\begin{array}{l}\text { "I learned something } \\
\text { new" } \\
\text { "It prompted me to } \\
\text { investigate more" }\end{array}$ & $\begin{array}{l}\text { Did not read original } \\
\text { publication, but other } \\
\text { articles. } \\
\text { Added to knowledge. } \\
\text { Evidence for future } \\
\text { decision-making. }\end{array}$ & $\begin{array}{l}\text { In this case, investigating more } \\
\text { meant reading other articles. } \\
\text { Watching and waiting in the } \\
\text { workplace instead of an } \\
\text { immediate change in practice. }\end{array}$ \\
\hline $\mathrm{P}-83$ & $\begin{array}{l}\text { "I learned something } \\
\text { new." } \\
\text { "It prompted me to } \\
\text { investigate more." }\end{array}$ & $\begin{array}{l}\text { Influenced thinking. } \\
\text { Read original article. } \\
\text { Shared information } \\
\text { with colleagues. }\end{array}$ & $\begin{array}{l}\text { The instrument did not capture } \\
\text { the sharing of information. }\end{array}$ \\
\hline P-89 & $\begin{array}{l}\text { "I learned something } \\
\text { new." } \\
\text { "I recalled something } \\
\text { I already knew." } \\
\text { "It prompted me to } \\
\text { investigate more." } \\
\text { "Knowledge-Other." } \\
\text { Eventually influence } \\
\text { others through } \\
\text { presentations and } \\
\text { publications. }\end{array}$ & $\begin{array}{l}\text { Read full article. } \\
\text { Presented at } \\
\text { conference. }\end{array}$ & $\begin{array}{l}\text { Participant not a librarian, but a } \\
\text { professor in LIS, so impacts } \\
\text { may be different. }\end{array}$ \\
\hline P-90 & "I was reassured." & $\begin{array}{l}\text { Saved time, did not } \\
\text { read original } \\
\text { publication (because } \\
\text { low level of evidence). } \\
\text { Discussed with } \\
\text { colleagues. }\end{array}$ & $\begin{array}{l}\text { Instrument did not capture } \\
\text { sharing with others. }\end{array}$ \\
\hline
\end{tabular}

Table 3: Examples of interview findings mapped to impact statements from the survey 


\subsection{Findings related to tool validation}

In addition to coding the interview transcripts to determine if they matched with the previously identified impact statements, the researchers also considered whether there were any other impacts that should be incorporated into the instrument. Most of the impacts reported in the survey were confirmed. Some of the impact statements perhaps could have benefited from better wording and required clarification in a revised version of the survey. The confirmation and possible revisions and additions to the initially proposed impact statements are provided in Table 4.

\begin{tabular}{|c|c|c|c|}
\hline Proposed impacts & $\begin{array}{l}\text { Survey: } \\
\text { Confirmed } \\
\text { impacts }\end{array}$ & $\begin{array}{l}\text { Interviews: } \\
\text { Confirmed } \\
\text { impacts }\end{array}$ & $\begin{array}{l}\text { Interviews: } \\
\text { Suggested / additional } \\
\text { impacts }\end{array}$ \\
\hline \multirow[t]{2}{*}{ Practice was improved } & $?$ & - & \\
\hline & & & Discovery \\
\hline Learned something new & + & + & \\
\hline Recalled something & + & + & \\
\hline Prompted to investigate & + & + & \\
\hline Confirmed & + & + & \\
\hline \multirow[t]{2}{*}{ Reassured } & + & $?$ & \\
\hline & & & Sharing \\
\hline Dissatisfied - presentation & $?$ & 0 & \\
\hline Dissatisfied - content & 0 & 0 & \\
\hline Potentially harmful & 0 & 0 & \\
\hline \multicolumn{4}{|l|}{ Other } \\
\hline Service & + & + & Individual practice \\
\hline Collections & + & 0 & \\
\hline Management & + & 0 & \\
\hline Teaching & + & 0 & \\
\hline \multirow[t]{2}{*}{ Professional practice } & + & + & \\
\hline & & & Assistance \\
\hline \multirow[t]{2}{*}{ Other } & 0 & 0 & \\
\hline & & & Workplace practice \\
\hline Library users & $?$ & $?$ & \\
\hline \multicolumn{4}{|c|}{$\begin{array}{l}\text { - Impact not well defined } \\
\text { + Impact confirmed } \\
\text { 0 Impact not recorded, but not disconfirmed } \\
\text { ? Impact unclear, no concrete examples identified }\end{array}$} \\
\hline
\end{tabular}

Table 4: Impact statements confirmed, suggested, and revised based on survey and interview findings.

The impact statement "It prompted me to investigate further" was operationalised through one of several possible activities: participants reported having gone on to read the original publication which the evidence summary appraised, to read more articles on the topic, or to engage in watchful waiting in the workplace.

A possible additional knowledge impact of reading an evidence summary that was identified during the interviews was that of discovery. Interview participants described this impact as involving the discovery of new research, interesting 
topics, and research methods in LIS, as well as current awareness more generally.

Another additional knowledge impact identified was that of sharing information. This impact was not captured by any of the impact statements on the instrument but was mentioned by several different interview participants. Examples of sharing included recommending the evidence summary to colleagues, summarising the information in a report or literature review, and sharing the findings with a group (for example, in a committee meeting).

An additional practice impact that was described by one participant was that of assistance. This impact took the form of assisting with research, writing, or presentation preparation, as well as assisting with teaching (for LIS academics).

A practice impact raised in the interviews but not captured by the instrument involved the teaching and learning of students in LIS. This is likely because the instrument was designed for use with LIS practitioners rather than academics and thus did not intend to capture these types of changes in practice. Nevertheless, it is interesting to see that the evidence summaries can be used in this way.

The list of impact statements from the initially proposed assessment instrument was evaluated in terms of its validity in describing possible impacts of reading evidence summaries by library and information professionals. Some of the statements were confirmed, while others needed revisions, or further testing, due to either an absence of occurrences in the critical incidences, or to a lack of concrete, measurable examples.

\section{Discussion}

This study demonstrates successful development and validation of an instrument to provide evidence of impact of evidence summaries on LIS practice. Overall, the findings suggest that individual librarians' knowledge has been and can be impacted in several ways as a result of reading evidence summaries. The impacts on librarians' knowledge were almost always positive, finding new or providing reassuring information. This is in line with the Grad, Pluye and Beauchamp (2006) findings on cognitive impacts in relation to summaries of evidence in health care. More research using the instrument could reveal potentially harmful impacts which Grad, Pluye and Beauchamp (2006) found, but our survey did not.

The findings suggest that evidence summaries can also impact on practice, both at the individual level (for a librarian) and at the group level (library, department, or organisation). Distinguishing between these two levels of practice impacts allows for more granular description of impacts. These modest changes in practice are in line with Kunz et al. (2007) in relation to discharge medication and Majumdar, Tsuyuki and McAlister (2007) for prescriptions. Finally, while the findings suggest that LIS practitioners believe that reading evidence summaries can have an impact on library users, further, more specific assessment is required to confirm this effect.

An unexpected but positive finding which emerged from the interviews was the impact of evidence summaries on academic LIS staff. Our survey questions were concerned with LIS practitioners and thus did not investigate this impact, but academics also use evidence summaries and incorporate what they learn into their 
teaching, or use the actual evidence summaries themselves in teaching, so it could be argued that the instrument should incorporate this dimension. However, given that the instrument is aimed at practice and the impact on future practitioners will be in the long term, this dimension has not been incorporated at this time.

The findings from this study therefore suggest four types or levels of impact: librarian knowledge, librarian practice, workplace practice, and library users and thus may overcome some of the gaps between research and practice identified by Haddow and Klobas (2004) as well as being accessible to practitioners a need identified by Eve and Schenk (2006).

The study provides evidence of face and content validity of the instrument, and although more validity testing could be undertaken, the results to date are promising particularly in relation to cognitive and practice impact. The findings have led to a revised instrument (Figure 1), which can be used to evaluate further the impact of evidence summaries. Furthermore, the instrument may be useful for other applications or resources which dissemination research findings or could be adapted by LIS practitioners to evaluate the impact of the services they provide.

\section{Evidence summary title:}

1. What was the impact of this evidence summary on your knowledge? (Select all that apply)

$\square$ I discovered something.

$\square$ I learned something new.

$\square$ I recalled something I already knew.

$\square$ It prompted me to investigate more.

$\square$ It confirmed I did (I am doing) the right thing.

$\square$ I was reassured.

$\square$ I shared information.

$\square$ My individual practice was (will be) improved. $\rightarrow$ See question 2

$\square$ My workplace practice was (will be) improved. $\rightarrow$ See question 3

$\square$ I was dissatisfied as this evidence summary had (will have) no impact on my practice.

$\square$ I was dissatisfied as there was a problem with this evidence summary.

$\square$ I disagree with this evidence summary.

$\square$ It is potentially harmful. $\rightarrow$ See question 4

$\square$ It had (will have) no impact at all on me or my practice.

$\square$ Other (specify:)

2. You reported: My individual practice was (will be) improved. What was (or will be) the impact on your individual practice as a result of reading the evidence summary?

(Select all that apply) 


\section{$\square$ Change my service approach}

$\square$ Change my approach to collections

$\square$ Change my management approach

$\square$ Change my approach to teaching

$\square$ Change my professional approach

$\square$ Other (please specify:)

3.You reported: My workplace practice was (will be) improved. What was (or will be) the impact on your workplace practice as a result of reading the evidence summary?

(Select all that apply)

$\square$ Change in workplace service approach

$\square$ Change in workplace approach to collections

$\square$ Change in workplace management approach

$\square$ Change in workplace approach to teaching

$\square$ Change in workplace professional approach

$\square$ Other (please specify:)

4. You reported: I was dissatisfied as there was a problem with this information. Which of the following problems did you encounter?

(Select all that apply)

$\square$ Too much information

$\square$ Not enough information

$\square$ Information poorly written

$\square$ Information too technical

$\square$ Other (please specify:)

5. If reading this evidence summary resulted in some change to your individual or workplace practice, do you think it led to an impact on library users? Please explain.

Figure 1: Revised impact assessment instrument for evidence summaries in LIS

\subsection{Limitations}

Findings from this study could be extended by sampling a larger group of evidence summary readers, both new and experienced. In addition, the critical incident technique employed for this survey instructed participants to select one evidence summary for which to report on impacts. This reduced the amount of data that could be collected from this sample as some respondents had read up to 10 evidence summaries in a 12 month period. However, asking participants to report on 10 evidence summaries would not allow individual impacts to be tracked for each evidence summary. Future research could include ongoing data 
collection for each evidence summary reader or a repeat of the survey on an annual basis to identify trends over time.

The timing of the survey with respect to the date of the critical incident may have had an effect on participants' recall. When asking about impacts on knowledge, participants may be more likely to recall these for evidence summaries read in the recent past. Conversely, for impacts on practice, these are more likely to have taken place once some time has passed since reading the evidence summary.

\section{Conclusion and implications}

This international study provides unique insight into how LIS practitioners are using research evidence in practice and whether evidence summaries are an effective means of bridging the research-practice gap and improving knowledge translation. Impacts were overwhelmingly positive, suggesting that evidence summaries make an impact on librarians' knowledge and their practice, both at an individual and workplace level. However, the impact of evidence summaries on library users was difficult to determine. A revised impact assessment instrument has been provided which may be useful for determining the different types of impact that arise from reading evidence summaries.

The study offers compelling evidence of the value of providing evidence summaries in the Evidence Based Library and Information Practice journal and highlights a potential need to improve marketing or packaging of the evidence summaries to ensure that they reach the intended audience and achieve maximum impact on practice.

\section{References}

Abels, E.G., Cogdill, K.W. and Zach, L. (2004) Identifying and communicating the contributions of library and information services in hospitals and academic health sciences centers, Journal of the Medical Library Association [online], 92(1), 46-55. URL: http://www.ncbi.nlm.nih.gov/pmc/articles/PMC314102/ [accessed 25.03.14].

Brettle, A. (2007) Evaluating information skills training in health libraries: a systematic review, Health Information and Libraries Journal, 24(Suppl 1), 18-37.

Brettle, A. (2009) Exploring the impact of the information professional on evidence based practice. In: Positioning the Profession: the Tenth International Congress on Medical Librarianship, Brisbane, Australia, 1-9, August 31 September 4, 2009. URL: https://espace.library.uq.edu.au/view/UQ:179846 [accessed 7.3.15].

Brettle, A., Maden-Jenkins, M., Anderson, L., McNally, R., Pratchett, T., Tancock, J., Thornton, D. and Webb, A. (2011) Evaluating clinical librarian services: a systematic review, Health Information and Libraries Journal, 28, 3-22.

Buckley Woods, H. and Booth, A. (2013) What is the current state of practitioner research? The 2013 LIRG research scan, Library and Information Research [online], 37(116). URL: 
http://www.lirgjournal.org.uk/lir/ojs/index.php/lir/article/view/598 [accessed 25.03.14].

Cruikshank, P., Hall, H. and Taylor-Smith, E. (2011) Enhancing the impact of LIS Research Projects: RiLIES Project Report, Research Information Network and LIS Research Coalition. URL:

http://lisresearchcoalition.files.wordpress.com/2012/02/rilies1 report.pdf [accessed 25.03.14].

Cullen, R. and Esson, R. (2007) Assessing the impact of information services in the health sector, Health Information and Libraries Journal, 24(Suppl.1), 1-3.

Dunne, M., Nelson, M., Dillon, L., and Galvin, B. (2013) Library value and impact: taking the step from knowing it to showing it, Library and Information Research [online], 37(116). URL:

http://www.lirgjournal.org.uk/lir/ojs/index.php/lir/article/view/577 [accessed 25.03.14].

Eve, J. and Schenk, N. (2006) Research and practice: findings from the Interactions project, Library and Information Research, 30(96), 36-46.

Grad, R., Pluye, P. and Beauchamp, M.-E. (2006) Validation of a method to assess the clinical impact of electronic knowledge resources, e-Service Journal, 5(2), 113-135.

Grad, R., Pluye, P., Johnson-Lafleur, J., Granikov, V., Shulha, M., Bartlett, G. and Marlow, B. (2011) Do family physicians retrieve synopses of clinical research previously read as email alerts? Journal of Medical Internet Research, 13(4), e101.

Haddow, G. and Klobas, J. E. (2004) Communication of research to practice in library and information science: closing the gap, Library and Information Science Research, 26, 29-43.

Hall, H. (2011) UK library and information science research matters, Library and Information Science Research, 33(1), 89-91.

Khangura, S., Konnyu, K., Cushman, R., Grimshaw, J. and Moher, D. (2012)

Evidence summaries: the evolution of a rapid review approach, Systematic

Reviews [online], 1(10). URL:

http://www.systematicreviewsjournal.com/content/1/1/10 [accessed 25.03.14].

Koufogiannakis, D. (2006) Small steps forward through critical appraisal, Evidence Based Library and Information Practice [online], 1(1), 81-82. URL: http://ejournals.library.ualberta.ca/index.php/EBLIP/article/view/26/64 [accessed 8.3.15].

Kunz, R., Wegscheider, K., Guyatt, G., Zielinski, W., Rakowsky, N., DonnerBanzhoff, N., and Müller-Lissner, S. (2007) Impact of short evidence summaries in discharge letters on adherence of practitioners to discharge medication. A cluster- randomised controlled trial, Quality and Safety in Health Care, 16, 456461.

Majumdar, S.R., Tsuyuki, R.T. and McAlister, F.A. (2007) Impact of opinion leader-endorsed evidence summaries on the quality of prescribing for patients 
with cardiovascular disease: a randomized controlled trial, American Heart Journal, 153(1), e1-8.

Markless, S. and Streatfield, D. (2006) Evaluating the impact of your library. London: Facet Publishing.

Marshall, J. G. (1995) Using evaluation research methods to improve quality, Health Libraries Review, 12(3), 159-172.

McGowan, J., Hogg, W., Campbell, C. and Rowan, M. (2008) Just-in-time information improved decision-making in primary care: a randomized controlled trial, PLoS ONE [online], 3(11), e3785. URL:

http://journals.plos.org/plosone/article?id=10.1371/journal.pone.0003785 [accessed 8.3.15].

Pluye, P., Grad, R.M., Johnson-Lafleur, J., Bambrick, T., Burnand, B., Mercer, J., Marlow, B. and Campbell, C. (2010) Evaluation of email alerts in practice: Part 2 - validation of the Information Assessment Method (IAM), Journal of Evaluation in Clinical Practice, 16(6), 1236-1243.

Pluye, P., Grad, R.M., Repchinsky, C., Farrell, B., Johnson-Lafleur, J., Bambrick, T., Dawes, M., Bartlett, G., Rodriguez, C., Jovaisas, B., Fortin, K., Tufts-Conrad, D., Salsberg, J., Macaulay, A., Légaré, F. and Loiselle, C. (2009) IAM: a comprehensive and systematic information assessment method for electronic knowledge resources. In: Dwivedi, A. (ed.) Handbook of Research on IT Management and Clinical Data Administration in Healthcare. Hershey: IGI Publishing. Chapter XXXIII.

Pluye, P., Grad, R.M., Stephenson, R. and Dunikowski, L.G. (2005) A new impact assessment method to evaluate knowledge resources. In: AMIA 2005 Symposium Proceedings, 609-613. URL:

http://www.ncbi.nlm.nih.gov/pmc/articles/PMC1560543/ [accessed 15.10.13].

Urquhart, C. (2004) How do I measure the impact of my service? (Guideline). In: Booth, A. and Brice, A. (eds.) Evidence Based Practice for Information Professionals: a Handbook. London: Facet. Special topic D.

Urquhart, C., Light, A., Thomas, R., Barker, A., Yeoman, A., Cooper, J., Armstrong, C., Fenton, R., Lonsdale, R. and Spink, S. (2003) Critical incident technique and explicitation interviewing in studies of information behavior, Library and Information Science Research, 25(1), 63-88

Weightman, A. and Williamson, J. (2005) The value and impact of information provided through library services for patient care: a systematic review, Health Information and Libraries Journal, 22, 4-25.

Weightman, A., Urquhart, C., Spink, S. and Thomas, R. (2008) The value and impact of information provided through library services for patient care: developing guidance for best practice, Health Information and Libraries Journal, 26, 63-71.

Williams, G.J., Sureshkumar, P., Wheeler, D. and Craig, J.C. (2010)

Paediatrician's responses to an evidence summary about renal tract imaging tests 
in children after urinary tract infection, Archives of Disease in Childhood, 95(4), 271-275.

Wyer, P.D. and Rowe, B. (2007) Evidence-based reviews and databases: are they worth the effort? Developing evidence summaries for emergency medicine, Academic Emergency Medicine, 14, 960-964.

\section{Acknowledgement}

The authors wish to acknowledge the support of the Canadian Association of Research Libraries (CARL) Research in Librarianship Grant, and McGill University for Dr. Kloda's sabbatical leave.

\section{Open access and copyright}

Library and Information Research is an open access journal. A freely available copy of this paper may be downloaded from the journal's website: http://www.lirgjournal.org.uk.

Copyright and associated moral rights in works published in Library and Information Research are retained by the author(s) but this paper may be used freely, with proper attribution, in educational and other non-commercial settings. 